\title{
Evaluating outcomes of management targeting the recovery of a migratory songbird of conservation concern
}

\author{
Henry M Streby ${ }^{\text {Corresp.. }}{ }^{1}$ ， Gunnar R Kramer ${ }^{1}$ ， Sean M Peterson ${ }^{2}$ ， David E Andersen ${ }^{3}$ \\ 1 Department of Environmental Science, University of Toledo, Toledo, Ohio, United States \\ 2 Department of Environmental Science, Policy and Management, University of California, Berkeley, Berkeley, California, United States \\ 3 Minnesota Cooperative Fish and Wildlife Research Unit, United States Geological Survey, St. Paul, Minnesota, United States \\ Corresponding Author: Henry M Streby \\ Email address: henrystreby@gmail.com
}

Background. Assessing outcomes of habitat management is critical for informing and adapting conservation plans. From 2013 - 2019, a multi-stage management initiative, led by the American Bird Conservancy $(A B C)$, aims to create $>25,000$ ha of shrubland and early-successional vegetation to benefit Golden-winged Warblers (Vermivora chrysoptera) in managed forested landscapes of the western Great Lakes region. We studied a dense breeding population of Golden-winged Warblers at Rice Lake National Wildlife Refuge (NWR) in Minnesota, USA, where ABC initiative management was implemented to benefit the species.

Methods. We monitored abundance before (2011 - 2014) and after (2015 - 2016) management, and we estimated full-season productivity (i.e., young recruited into the fall population) from predictive, spatially explicit models, informed by nest and fledgling survival data collected at sites in the western Great Lakes region, including Rice Lake NWR, during 2011 and 2012. Then, using biologically informed models of bird response to observed and predicted vegetation succession, we estimated the cumulative change in population recruitment over various scenarios of vegetation succession and demographic response.

Results. We observed an $32 \%$ decline in abundance of breeding pairs and estimated a $27 \%$ decline in per-pair full-season productivity following management, compared to no change in a nearby control site. In models that ranged from highly optimistic to progressively more realistic scenarios, we estimated a net loss of 72 - 460 juvenile Golden-winged Warblers produced from the managed site in the $10-20$ years following management. Even if our well-informed and locally validated productivity models produced erroneous estimates and the management resulted in only a temporary reduction in abundance (i.e., no change in productivity), our forecast models still predicted a net loss of $137-260$ juvenile Golden-winged Warblers from the managed area over the same time frame.

Conclusions. Our study site represents only a small portion of a massive management initiative; however, the management at our site was conducted in accordance with the initiative's management plans, the resulting vegetation structure is consistent with that of other areas managed under the initiative, and those responsible for the initiative have described the management at our study site as successful Golden-winged Warbler management. Our assessment demonstrates that, at least for the only site for which pre- and post-management data on Golden-winged Warblers exist, the ABC management initiative is having a substantial and likely enduring negative impact on the species it purports to benefit. We suggest that incorporating region-specific, empirical information about Golden-winged Warbler-habitat relations into habitat management efforts would increase the likelihood of a positive response by Golden-winged Warblers. 
1 Disclosure: This draft manuscript is distributed solely for purposes of scientific peer review. Its 2 content is deliberative and predecisional, so it must not be disclosed or released by reviewers.

3 Because the manuscript has not yet been approved for publication by the U.S. Geological Survey

4 (USGS), it does not represent any official USGS finding or policy.

5

6 Evaluating outcomes of management targeting the recovery of a migratory songbird of 7 conservation concern

8

9 Henry M. Streby ${ }^{1}$, Gunnar R. Kramer ${ }^{1}$, Sean M. Peterson ${ }^{2}$, and David E. Andersen ${ }^{3}$

${ }^{1}$ Department of Environmental Sciences, University of Toledo, Toledo, Ohio, USA.

${ }^{2}$ Department of Environmental Science, University of California, Berkeley, California, USA.

${ }^{3}$ U.S. Geological Survey, Minnesota Cooperative Fish and Wildlife Research Unit, St. Paul,

Minnesota, USA

15

Corresponding Author

Henry Streby ${ }^{1}$

18

Email address: henrystreby@gmail.com 


\section{Abstract.}

Background. Assessing outcomes of habitat management is critical for informing and adapting conservation plans. From 2013 - 2019, a multi-stage management initiative, led by the American Bird Conservancy $(\mathrm{ABC})$, aims to create $>25,000$ ha of shrubland and early-successional vegetation to benefit Golden-winged Warblers (Vermivora chrysoptera) in managed forested landscapes of the western Great Lakes region. We studied a dense breeding population of Golden-winged Warblers at Rice Lake National Wildlife Refuge (NWR) in Minnesota, USA, where ABC initiative management was implemented to benefit the species.

Methods. We monitored abundance before (2011 - 2014) and after (2015 - 2016) management, and we estimated full-season productivity (i.e., young recruited into the fall population) from predictive, spatially explicit models, informed by nest and fledgling survival data collected at sites in the western Great Lakes region, including Rice Lake NWR, during 2011 and 2012. Then, using biologically informed models of bird response to observed and predicted vegetation succession, we estimated the cumulative change in population recruitment over various scenarios of vegetation succession and demographic response.

Results. We observed an $32 \%$ decline in abundance of breeding pairs and estimated a $27 \%$ decline in per-pair full-season productivity following management, compared to no change in a nearby control site. In models that ranged from highly optimistic to progressively more realistic scenarios, we estimated a net loss of $72-460$ juvenile Golden-winged Warblers produced from the managed site in the $10-20$ years following management. Even if our well-informed and locally validated productivity models produced erroneous estimates and the management resulted in only a temporary reduction in abundance (i.e., no change in productivity), our forecast models still predicted a net loss of 137 - 260 juvenile Golden-winged Warblers from the managed area over the same time frame. 
58 Conclusions. Our study site represents only a small portion of a massive management initiative;

59 however, the management at our site was conducted in accordance with the initiative's management

60 plans, the resulting vegetation structure is consistent with that of other areas managed under the

61 initiative, and those responsible for the initiative have described the management at our study site as

62 successful Golden-winged Warbler management. Our assessment demonstrates that, at least for the

63 only site for which pre- and post-management data on Golden-winged Warblers exist, the ABC

64 management initiative is having a substantial and likely enduring negative impact on the species it

65 purports to benefit. We suggest that incorporating region-specific, empirical information about

66 Golden-winged Warbler-habitat relations into habitat management efforts would increase the

67 likelihood of a positive response by Golden-winged Warblers.

68

69

70

71

72

73

74

75

76

77

78

79

80

\section{Introduction}

Many species of birds associated with shrubland and early-successional forest cover types are experiencing long-term declines in abundance across eastern North America (Sauer et al. 2014). 
81 Golden-winged Warblers (Vermivora chrysoptera) are a Nearctic-Neotropical migratory species

82

83 experiencing one such decline (Figure 1, Sauer et al. 2014). Although no cause of population decline has definitive empirical support, competing hypotheses attribute the declines to breeding-grounds factors such as a reduction in shrubland and young forest area and competition and hybridization with Blue-winged Warblers (Vermivora cyanoptera; Rohrbaugh et al. 2016) and non-breeding factors such as geographic isolation and regional habitat conditions on the wintering grounds (Kramer et al. 2017), and possibly some combination of these factors.

Golden-winged Warblers breed in isolated, high-elevation areas along the Appalachian Mountains and more densely throughout the western Great Lakes region (Buehler et al. 2007; Rosenburg et al. 2016). Breeding densities of this species generally increase from east to west, with Minnesota hosting nearly half of the global population in $13 \%$ of the known breeding distribution (Rosenburg et al. 2016). Regional variation in Golden-winged Warbler population declines has likely led to this east-west density gradient, as Appalachian states have experienced declines of $>95 \%$ since 1965 while Minnesota has seen stable or slightly increasing populations over the same period (Figure 1; Zlonis et al. 2013; Sauer et al. 2014; Rosenberg et al. 2016). This places a strong stewardship responsibility on the state of Minnesota and other jurisdictions in the western Great Lakes region for Golden-winged Warbler conservation as the species is considered for listing under the Federal Endangered Species Act (Peterson et al. 2016a).

In response to long-term declines in Golden-winged Warbler numbers, many studies have been conducted in attempts to inform conservation strategies that might reverse negative population trends (Buehler et al. 2007; Rohrbaugh et al. 2016). These studies, primarily conducted in the Appalachian Mountains segment of the breeding distribution, have detailed habitat characteristics associated with breeding Golden-winged Warblers from the regional scale (Crawford et al. 2016) to 
104 the scale of 1-m plots at nest locations (Aldinger et al. 2015; Terhune et al. 2016) and many scales in 105 between (Rossell et al. 2003; Kubel \& Yahner 2008; Bulluck \& Buehler 2008; Confer et al. 2010; Aldinger \& Wood 2014). Although some differences in results may be attributable to differences in

107

108

109

110

111

112

113

114

115

116

117

118

119

120

121

122

123

124

125

methods and variables measured among studies, a generalizable conclusion from the studies that

used standardized methods across sites is that breeding habitat structure for Golden-winged Warblers varies among sites, states, and regions, and that site-by-site conservation plans may be required (Terhune et al. 2016; Streby et al. 2016).

In 2013 (planned through 2019), multiple large-scale management initiatives began working to manage public and private forested areas to benefit Golden-winged Warblers in the western Great Lakes region. In July 2013, the American Bird Conservancy (ABC) and partners were awarded $\$ 4.7 \mathrm{M}$ to implement management on public and private lands in Minnesota to benefit Goldenwinged Warblers (http://www.legacy.leg.mn). In January 2015, ABC announced a \$10M partnership with the U.S. Department of Agriculture's Natural Resource Conservation Service (NRCS) to incentivize and implement the same management prescriptions on private lands in Minnesota and Wisconsin (www.abcbirds.org). Together, these initiatives (hereafter; ABC initiative) have the stated goal of managing $>26,000$ ha within the primarily forested landscape of the western Great Lakes region focused on creating breeding habitat for Golden-winged Warblers (Johns et al. 2015, Larkin et al. 2016). The ABC initiative predicted it would "create new breeding habitat for 1,180 breeding pairs of Golden-winged Warblers" and "result in an increase of 16,000 individuals within four years" (Johns et al. 2015, pg 1). The primary focal area of this initiative is the northern hardwoodboreal forest transition zone of northern Minnesota. Forested private and public lands are targeted with financial incentives, and although landscape context is important to songbird conservation 
126 (Donner et al. 2010, Bonnot et al. 2013), management has been conducted at accessible sites without 127 consideration of the surrounding mosaic (P. Diesser, personal communication).

It is critical to monitor effects of focal-species management so that methods can be replicated

129

130

131

132

133

134

135

136

137

138

139

140

141

142

143

144

145

146

147

148

when successful (Lyons et al. 2008) and learned from when not successful (Hiers et al. 2016). It is

particularly important that conservation actions benefit focal species because policies and plans that are poorly informed and poorly implemented can accelerate the loss of biodiversity (Woinarski et al. 2017). The ABC initiative is occurring in a portion of the Golden-winged Warbler breeding distribution that currently supports the bulk of breeding Golden-winged Warblers and lessons from this initiative are potentially beneficial for informing Golden-winged Warbler management where their populations are in peril. The ABC initiative's management is guided by regional Best Management Practices for Golden-winged Warblers (Larkin et al. 2016), based on a Golden-winged Warbler conservation plan (Roth et al. 2012). Although Minnesota hosts approximately half of the global breeding population of Golden-winged Warblers, $>95 \%$ of the data used to inform the Roth et al. (2012) plan was collected in the nearly extirpated Appalachian Mountains breeding population segment. Therefore, timely assessment of the current management initiative is necessary both because of the immediate need for model management strategies for Golden-winged Warblers elsewhere and because of the potential for necessary adjustments during implementation due to the plan's reliance on Golden-winged Warbler-habitat relations derived from other portions of the breeding distribution.

As part of an ongoing study of Golden-winged Warbler-habitat relations in the western Great Lakes region, we had the fortuitous opportunity to study the response of Golden-winged Warblers to $\mathrm{ABC}$ initiative management intended to increase breeding abundance at Rice Lake National Wildlife Refuge (NWR) in east-central Minnesota. Our study is the only assessment of 
149 habitat management intended to benefit Golden-winged Warblers with extensive before- and after-

150 management information on habitat use and population dynamics, and therefore may provide insight

151 into the potential response of Golden-winged Warblers to management intended to increase

152 population size and productivity.

153 We monitored abundance of breeding pairs in a managed area within Rice Lake NWR for 4

154 years prior to management and 2 years after management. In addition, because abundance alone can

155 be a misleading indicator of habitat quality (Van Horne 1983), we used biologically informed,

156 spatially explicit models of full-season productivity (i.e., young recruited into the fall population;

157 Peterson et al. 2016a) of Golden-winged Warblers before and after management to estimate changes

158 in productivity in response to management. Our study represents only 2 sites (one managed and one

159 control) within the large ABC management initiative, and we present our assessment with

160 uncertainty about its application to the broader initiative outcomes. However, the management at our

161 study site is described by the implementers as identical to that applied elsewhere in Minnesota and is

162 reported as a successful management site (Larkin et al. 2016), so it is reasonable to conclude that the

163 outcomes at our site are not unique.

164

165

Materials and Methods

166 Study Area

167 We studied Golden-winged Warblers at 2 sites within Rice Lake NWR $\left(46.529^{\circ} \mathrm{N}, 93.338^{\circ} \mathrm{W}\right)$ in

168 Aitkin County, Minnesota, USA. Rice Lake NWR encompasses 7,300 ha of diverse cover types

169 including lakes, rivers, grassy and shrubby wetlands, bogs, upland and wetland forests of various

170 successional stages, and minimal agriculture. The refuge hosts some of the densest known areas of

171 breeding Golden-winged Warblers, including locations with $>1$ breeding pair / ha. Prior to ABC 
172 initiative management, our 80-ha main study site included 41 ha of shrubland and early-successional

173 forest cover types and supported 62 breeding pairs of Golden-winged Warblers, and our 30-ha

174 control site included 16 ha of shrubland and early-successional forest cover types and supported 19

175 breeding pairs of Golden-winged Warblers. Our main site and control site were separated by $2.0 \mathrm{~km}$

176 and some of the area between sites was also occupied by Golden-winged Warblers. Both study sites

177 combined supported 1 pair per 0.7 ha of shrubby cover types with which the species is typically

178 associated as a habitat specialist (Ficken \& Ficken 1968; Confer et al. 2011), and we are unaware of

179 any more densely populated area within the Golden-winged Warbler breeding distribution.

180 Prior to ABC initiative management, vegetation in our study area was a diverse and patchy

181 mix of trees, shrubs, sedges, and forbs with soft, feathered-edge (i.e. small-scale complexity)

182 transitions between shrubby areas and later-successional forest (Figure 2). The vegetative structure

183 of the shrublands in our study area was naturally maintained by poor soils, no management had

184 occurred on our main site in at least the previous 13 years (W. Ford, personal communication, and 185 the authors, personal observation using Google Earth ${ }^{\circledR}$ ), and some trees and shrubs $<5 \mathrm{~m}$ tall had 186 growth rings indicating they ranged from $10-25$ years old (The authors, personal observation 187 following management). Common trees in later-successional forest stands included sugar maple 188 (Acer saccharum), red maple (A. rubrum), quaking aspen (Populus tremuloides), bigtooth aspen $(P$. 189 grandidentata), paper birch (Betula papyrifera), American basswood (Tilia americana), bur oak 190 (Quercus macrocarpa), and red oak (Q. Rubra). Shrubland and young forest stands were a complex 191 mix of willow (Salix spp.), hazelnut (Corylus spp.), dogwood (Cornus spp.), paper birch, quaking 192 and bigtooth aspen, grasses, sedges, and forbs with individual and small groups of young and mature 193 bur oak and red oak trees. The complexity and diversity of vegetation was reflective of the diversity 194 of soil types including hamre muck, Dysler silt loam, and talmoon fine sandy loam (NRCS Soil 
195 Survey 2016). Due to the dense, ephemerally wet, poorly drained nature of these soils, the trees and

196 shrubs of the managed area were slow growing, and there had been no discernable change in

197 vegetation structure or composition during the 4 years prior to treatment (The Authors, personal

198 observation) or for 5 years prior to our observations (A. Hewitt, personal communication).

\section{Management}

200 During the winter of 2014 - 2015, several areas were managed across Rice Lake NWR totaling 16

201 ha of which 12 ha were in our main study site and none were within our control site. Managed areas

202 were mechanically cleared of vegetation to ground level through hydro-axing during the winter

203 when frozen ground enabled accessibility, as per recommendations in the Golden-winged Warbler

204 Conservation Plan (Roth et al. 2012). The management was described as the clearing of overgrown

205 brush, which is the primary technique implemented on public lands in Minnesota during the ABC

206 initiative (Larkin et al. 2016, Diesser 2017). The resulting vegetation structure in the 2015 growing

207 season was dominated by patchy areas of sedges, forbs, bare ground, and woody debris, similar to

208 previous management by this method in Minnesota (Hanowski et al. 1999). The pre-management

209 soft, feathered transition into the surrounding later-successional forest was hydro-axed, resulting in a

210 hard, linear edge between the managed area and the surrounding forest. In 2016, the shorn stumps of

211 trees and shrubs began to re-sprout stem clusters creating low $(<0.25 \mathrm{~m})$, dense, homogenous areas of

212 woody stems within a mosaic of sedges and forbs (Figure 2). In 2017, the managed area was

213 dominated by a low $(0.25-0.50 \mathrm{~m})$, dense mat of dogwood, typical of other shrublands managed by

214 shearing in Minnesota (Hanowski et al. 1999). The goal of the vegetation management was to create

215 shrubby young forest with high complexity that would benefit Golden-winged Warblers within 4

216 years (Larkin et al. 2016). After 3 growing seasons, the managed area was visually similar to an

217 adjacent ephemeral wetland that was dominated by sedges and low shrubs and has not hosted 
218 Golden-winged Warblers during any of our observations. In other words, consistent with

219 management of the same prescription in previous decades in Minnesota (Hanowski et al. 1999), after

2203 years the managed area was far behind pace to contain the vegetation structure intended to be

221 produced within 4 years after management.

\section{Bird Abundance Monitoring}

223 From 2011 - 2016 we censused Golden-winged Warbler breeding pair abundance in the managed 224 area as part of 2 studies that involved individual marking of males and females (Streby et al. 2014;

225 Peterson et al. 2015). In 2011 - 2012 we monitored color-banded and radio-marked males and

226 females and delineated core breeding territories as part of a study on Golden-winged Warbler

227 demography (Streby et al. 2014; Streby et al. 2015; Peterson et al. 2016a), and in 2013 - 2016 we

228 monitored settlement patterns and territory occupancy during a study of migration ecology that

229 involved capturing, marking, and behavioral observations of breeding males and females (Peterson

230 et al. 2015). In each of those years, we monitored every pair of Golden-winged Warblers within our

231 study site and we are confident that we produced a complete census. Due to logistical constraints, we

232 did not assess Golden-winged Warbler abundance at these study sites in 2017, but only observed

233 vegetation structure.

\section{Productivity Modeling}

235 Data we used to inform productivity models were collected under protocols \#1004A80575 and

236 \#160333530A approved by the University of Minnesota Institutional Animal Care and Use

237 Committee, and research permits \#21631 (USGS Bird Banding Laboratory) and 19017 (Minnesota

Department of Natural Resources) during studies of nesting and post-fledging ecology of Golden-

winged Warblers in 2011 and 2012. We applied spatially explicit models of full-season productivity

240 (Peterson 2014; Peterson et al. 2016a) for Golden-winged Warblers and estimated the number of 
241 young recruited into the fall population under multiple scenarios. Our models were informed by data

242 about Golden-winged Warbler nest productivity ( $n=216$ nests) and fledgling survival ( $n=190$

243 fledglings) collected during a 2-year study at 3 sites in northern Minnesota and southeastern

244 Manitoba, including our study area at Rice Lake NWR (Peterson et al. 2016a). For field data

245 collection details, see Peterson (2014) and Peterson et al. (2016a). Briefly, we used radio-telemetry

246 monitoring of breeding females and standard nest-searching methods to locate Golden-winged

247 Warbler nests and monitor their fates. We radio-marked nestlings and used their fates before and

248 after fledging to determine nest success, fledged brood sizes, and fledgling survival rates during and

249 after dependence on adult care (Streby et al. 2014; Streby et al. 2015). We assessed the effects of

250 micro- and meso- scale habitat characteristics on nest and fledgling survival rates and found stand-

251 level effects (i.e., the identity and area of cover types around a nest) to be significantly more

252 influential on survival rates in both stages (Streby et al. 2014), and we therefore informed our full-

253 season productivity models with these larger-scale parameters as in Peterson (2014) and Peterson et

254 al. (2016a).

Step-by-step instructions and programming code for parameterization and implementation of

full-season productivity models are detailed in Appendix C of Peterson (2014) and further described

257

258

259

260

261

262

263

in Peterson et al. (2016a). Summarily, full-season productivity models are logistic exposure survival models (Shaffer 2004) that incorporate effects of landscape composition and configuration at statistically and biologically relevant scales on nest success and fledgling survival rates. In these models, the effect of each cover type on predicted nest success or fledgling survival rates varies depending on the presence and area of that cover type and other cover types at predetermined, biologically relevant, radii from any given location on the landscape. When combined, estimates of nest success, fledged brood size, renesting rates, and fledgling survival rate for every square meter in 
264 the landscape result in a spatially explicit map of full-season productivity for birds in an area of

265 interest. Specifically, full-season productivity models produce an estimate of the number of young

266 recruited into the fall migratory population per breeding pair in the modeled area. Multiplying the

267 full-season productivity estimate by the number of breeding pairs in the modeled area produces an

268 estimate of the number of young recruited into the fall population from the population of birds

269 breeding in the area of interest. By changing the shape, area, or cover type identity of any stand in

270 the modeled landscape, and then re-applying the model to the resulting landscape, one can estimate

271 full-season productivity for any hypothetical or real stand-level management scenario. These models

272 have been validated as meaningfully predictive for Golden-winged Warbler productivity data in our

273 study area (Peterson et al. 2016a) and we therefore expect their predictions of post-management

274 productivity to provide insight into how Golden-winged Warblers respond to changes in cover-type

275 composition resulting from management. Full-season productivity models were developed as an

276 improvement upon models including only nesting success because fledgling survival rate is an

277 increasingly appreciated component of songbird productivity (Streby et al. 2014), and fledgling

278 survival rate and nesting success can be influenced differently by the same habitat characteristics

279 (Cohen and Lindell 2004; Jackson et al. 2013; Streby et al. 2014), making the inclusion of fledgling

280 survival rate and habitat use critical management considerations (Peterson et al. 2016a and b).

281 We estimated full-season productivity for the managed area at Rice Lake NWR under 3

282 scenarios of forest succession: 1) rapid succession, 2) moderate succession, and 3) slow succession.

283 In each model scenario, we assumed that shrub and small tree density would regenerate to a state

284 similar to pre-management vegetation within 4 years (rapid; unlikely but assumed by the ABC

285 initiative), 10 years (moderate; possible based on historical succession), and 20 years (slow; likely

286 based on historical succession). In addition, we estimated full-season productivity in the absence of 
287 management (i.e., as if management had not occurred) to provide an estimate to which we could

288 compare the net effects of the range of post-management scenarios. In the no-management scenario,

289 we assumed the area would maintain similar, pre-management, vegetation structure for the entire

290 period, which is likely for all 3 scenarios given the soil types and vegetation succession history of

291 the managed area. It is possible that the complexity and vertical stratification of the pre-treatment

292 vegetation structure may not return in any of the post-management scenarios, but we assumed that

293 adequate shrub and small tree cover would regenerate by the end of each scenario to host pre-

294 treatment numbers of breeding Golden-winged Warblers. For each succession scenario we modeled

295 the response of Golden-winged Warbler productivity 2 ways. First, we assumed Golden-winged

296 Warbler productivity responded linearly with time in each scenario, which is likely given the

297 relationship between Golden-winged Warbler productivity and landscape composition and the slow

298 and approximately linear vegetation succession that occurs in our study area. Second, although there

299 is no evidence of density dependent changes in productivity in our study system, population theory

300 predicts that productivity should increase in response to reduced density. Therefore, in a second set

301 of scenarios, we assumed that after a brief initial negative response, Golden-winged Warbler

302 productivity would increase rapidly to a level $25 \%$ greater than pre-management productivity,

303

304

305

306

307

308

309

followed by a return to pre-management productivity by the end of each scenario period. Each of the various productivity scenarios included a linear response in density as described above. We did not consider models in which density responded in a parabolic fashion because our study sites hosted the greatest known densities of Golden-winged Warblers prior to management, and any increase in density is unlikely.

We assessed only abundance under post-management conditions for our control site (i.e., no productivity models applied) because we did not expect vegetation-based changes in productivity in 
310 the absence of management within any of our scenario time frames. Certainly, trees and shrubs will

311 grow larger on the control site and in our no-management scenario, but past succession rates indicate

312 it is unlikely that any shrub-dominated stands in our study area would succeed to forest-dominated

313 stands in the time frame of our models.

\section{Results}

315 During the pre-management breeding seasons of 2011-2014, our main study site hosted 62 pairs of 316 breeding Golden-winged Warblers each year (Figure 3) and our control site hosted 19 breeding pairs 317 each year. In 2015, the breeding season immediately following management, our main site hosted 45 318 breeding pairs of Golden-winged Warblers (Figure 3) and the control site hosted 19 pairs. One male that bred in the main site for 2 years prior to management, established a territory $2.6 \mathrm{~km}$ away in the

320 control site following management, apparently displacing or replacing the male that previously bred

321 in that control-site territory the previous year. In 2016, the second breeding season after

322 management, our main site again hosted 45 breeding pairs of Golden-winged Warblers (Figure 3)

323 and the control site again hosted 19 pairs. Within the main site, primary losses of breeding pairs

324 occurred in the middle of managed areas, and pairs remaining along the edges of managed areas

325 shifted core use areas away from managed vegetation and into adjacent later-successional forest 326 (Figure 3).

For all post-management scenarios, we included the observed 45 breeding pairs for 2015, 45 breeding pairs for 2016, and then included linear responses from 45 back to 62 breeding pairs in the remainder of the scenario period. For example, in the rapid succession scenario, 2015 and 2016 were included as the first 2 years after management, and our models assumed 53 breeding pairs in 2017 and 62 in 2018, to complete the return to pre-treatment abundance in 4 years after management. We

332 did the same for the moderate and slow succession scenarios including the first 2 years as observed 
333 and then return from 45 to 62 breeding pairs linearly over the subsequent 8 years and 18 years to

334 complete the scenario periods, respectively.

335 Prior to management, our main site produced an estimated $1.45( \pm 0.11)$ juveniles recruited

336 into the fall population per breeding pair each year (Figure 4). Given the abundance of 62 breeding

337 pairs, we estimated that $90( \pm 6)$ juvenile Golden-winged Warblers were recruited into the fall

338 population each year from this site prior to management. After management, the main site produced

339 an estimated $1.04( \pm 0.10)$ juveniles recruited into the fall population per breeding pair per year

340 (Figure 4). In our linear productivity models, we assumed productivity would return to pre-

341 management levels linearly with time and reach 1.45 fledglings per pair by the end of each scenario

342 period. Given the abundance of 45 breeding pairs in 2015 and the modeled $1.04( \pm 0.10)$ juveniles

343 per breeding pair, we estimated that $47( \pm 4)$ juvenile Golden-winged Warblers were recruited into

344 the fall population from this area in 2015, and the number of juveniles recruited into the fall

345 population increased as abundance and productivity increased linearly with time. In our density-

346 dependent productivity models, we used the same initial post-management abundance observations

347 and productivity estimates, but then assumed productivity increased relatively rapidly, peaking at

3481.81 juveniles per breeding pair (i.e., 25\% higher than pre-management productivity) and then

349 returned to the pre-management 1.45 juveniles per breeding pair by the end of each scenario (see

350 Supplementary data and analysis).

351

Under the rapid succession scenario, we estimated that $262( \pm 19)$ juvenile Golden-winged

352 Warblers were recruited into the fall population from the main site during the 4 years following

353 management, compared to $360( \pm 22)$ juveniles during the same period if management had not

354 occurred. Under the moderate succession scenarios, our linear productivity model estimated that 662

$355( \pm 48)$ juvenile Golden-winged Warblers were recruited into the fall population from the main site 
356 during the 10 years following management, compared to $825( \pm 59)$ juveniles estimated from the

357 density-dependent, parabolic productivity model and $900( \pm 64)$ juveniles during the same period if

358 management had not occurred. Under the slow succession scenario, we estimated that 1,340 $( \pm 96)$

359 juvenile Golden-winged Warblers were recruited into the fall population from the main site during

360 the 20 years following management, compared to 1,674 ( \pm 120$)$ juveniles estimated from the

361 density-dependent, parabolic productivity model and 1,800 $( \pm 129)$ juveniles during the same period

362 if management had not occurred. Therefore, in the rapid, moderate, and slow succession scenarios

363 we estimated that 12 ha of management from the $\mathrm{ABC}$ initiative resulted in a net loss of 98,238 , and

364460 juvenile Golden-winged Warblers under our linear productivity models, respectively, at the

365 managed site. Our density-dependent, parabolic productivity models estimated a net loss of 72

366 juveniles over 10 years or 96 juveniles over 20 years, compared to recruitment under our no-

367 management scenario.

368 Although our productivity models were informed by a sizeable, locally relevant, dataset and

369 have been validated as predictive of Golden-winged Warbler productivity in our study area (Peterson

370 et al. 2016a), we do not have direct measures of post-management productivity to confirm model

371 accuracy. However, even in a scenario under which only abundance, and not per-pair productivity,

372 was influenced by the management, our forecast models predicted a net loss of 61, 137, and 260

373 juvenile Golden-winged Warblers recruited into the managed population in the rapid, moderate, and

374 slow succession scenarios, respectively. There is no biologically plausible recruitment rate that this

375 population could reach within $10-20$ years after management that would compensate for the

376 immediate decline and expected slow recovery in breeding abundance.

\section{Discussion}


378 We observed an immediate decline in breeding Golden-winged Warbler abundance following

379 management consisting of hydro-axing dense and diversely stratified vegetation surrounded by later-

380 successional forest at Rice Lake NWR, while abundance remained unchanged at a nearby control

381 site. Our observations are consistent with Hanowski et al. (1999) who reported that mechanical

382 clearing of Minnesota shrublands had negative and persistent effects on occupancy and abundance of

383 shrubland and edge associated birds including Golden-winged Warblers. We did not include detailed

384 measurements and comparisons of vegetation structure before and after management because 1)

385 detailed vegetation structure descriptions of our study site are published (e.g. Peterson et al. 2016a),

386 2) Golden-winged Warbler productivity and survival relate to cover-type patch-scale habitat

387 characteristics more strongly than to microhabitat vegetation structure (Streby et al. 2014), and 3)

388 statistics are unnecessary for comparing the sizes of trees and shrubs to sedges and forbs (Johnson 389 1999).

390 Spatially explicit models of full-season productivity indicated a decline in per-pair

391 productivity concurrent with the decline in abundance after management. The initial decline in

392 productivity was associated primarily with increased area of grassland on the landscape, which has

393 negative effects on Golden-winged Warbler nest productivity and fledgling survival rate in most

394 landscape configurations in Minnesota (Peterson 2014) despite being identified as an important

395 habitat component at the micro-habitat scale in the Appalachian breeding distribution segment

396 (Terhune et al. 2016). Our model of an unlikely, 4-year recovery of the vegetation and return of bird

397 abundance and productivity to pre-management levels, based on the ABC initiative's stated timeline,

398 estimated a 27\% reduction in juvenile Golden-winged Warblers recruited into this population. Our

399 models of more likely scenarios of vegetation succession and bird response over 10 and 20 years

400 after management estimated that this population will produce $26 \%$ fewer juvenile Golden-winged 
401 Warblers over those periods than if the management had not occurred. These losses equate to $20-$

40238 Golden-winged Warblers lost per hectare of ABC initiative management at our study site. Even in

403 density-dependent, parabolic productivity models, in which productivity rapidly increased to $25 \%$

404 greater than pre-management levels and then returned to pre-management levels by the end of each

405 scenario, we still estimated a net loss of $5-8 \%$ in juveniles recruited over $10-20$ years post-

406 management, primarily because no realistic level of productivity could compensate for the

407 substantial decline in abundance. As a point of emphasis, our productivity estimates refer to the

408 number of young recruited into the fall migrating population and our models already include the

409 large amount of mortality that occurs during the post-fledging period; had we estimated productivity

410 by the more traditional measure of number of young fledged from nests, the negative effect on

411 productivity would appear greater in all scenarios.

412

It is unclear to us why large-scale vegetation management targeting Golden-winged Warblers

413 was initiated in Minnesota in general and at Rice Lake NWR in particular. During structured

414 decision making in management and conservation planning a critical initial step is to determine if

415 action is necessary (Lyons et al. 2008); the dense, highly productive, and stable or increasing

416 population of Golden-winged Warblers in Minnesota seems not to meet this criterion, and there was

417 not a denser population known than the one at our study site prior to management. We speculate that

418 this initiative may have been targeted in Minnesota in response to dramatized reports of the global

419 decline of Golden-winged Warblers without consideration of the great regional variation in

420 population trends including the long-term stability of the Minnesota population (e.g., Cornell Lab of

421 Ornithology 2016), and the expanded private landowner participation may be driven by erroneous

422 descriptions of the Minnesota population being in decline (e.g., MacSwain 2016). 
424 patches of diverse vegetation structure within otherwise contiguous mature forest areas would be the

425

426

427

428

429

430

431

432

433

434

435

436

437

recommended route based on extensive research on the species in Minnesota (Peterson et al. 2016a and b, Streby et al. 2016a). However, Minnesota already surpasses the percent forested area in earlysuccessional stages (i.e., 17\%) recommended by the conservation plan on which the $\mathrm{ABC}$ initiative management is based (Roth et al. 2012), and ongoing forest management in Minnesota has maintained or increased that percentage over at least the past 3 decades (Miles \& VanderSchaaf 2012). Simply hydro-axing vegetation that is currently ideally suited for dense and productive populations of Golden-winged Warblers, with the hope of somehow compensating in the long-run for the initial damage done, is indefensible in our opinion and predictably failing in our assessment. Additionally, increases in grassland area, even temporarily, potentially also compromise Minnesota's goals of managing and maintaining various successional stages of forest (Johnson et al. 2008) that provide resources for many species of birds during the nesting (Niemi et al. 2016) and post-fledging periods (Streby et al. 2011) in a region that has already experienced long-term losses in forest functional and structural heterogeneity (Schulte et al. 2007).

Although Minnesota hosts approximately half of the global breeding population of Goldenwinged Warblers, only 4\% (18 out of 412 nesting territories) of the data used to inform the Roth et al. (2012) conservation plan were collected in Minnesota and no information regarding post-fledging habitat requirements was included in that plan. Studies on Golden-winged Warblers in Minnesota have demonstrated the importance of later-successional forest during the nesting season (Streby et al. 2012), the dependent post-fledging period (Peterson 2014, Streby et al. 2014, Peterson et al. 2016a), and for fledglings after independence from adult care (Streby et al. 2015). Given the lack of information derived from this core area of Golden-winged Warbler breeding density in the Roth et 
446 al. (2012) conservation plan, it is surprising that the Upper Mississippi River and Great Lakes Joint

447 Venture concluded that "Golden-winged Warbler needs are met" for the region by the Roth et al.

448 (2012) conservation plan (http://www.uppermissgreatlakesjv.org/Priorities). Even in areas where the

449 Roth et al. (2012) conservation plan includes locally relevant data, such as the Pocono Mountains of

450 eastern Pennsylvania, Golden-winged Warblers continue to decline despite large-scale management

451 actions (Fearer 2016). These continued declines in the Appalachian segment of the species' breeding

452 distribution suggest that management is not addressing the factors driving population declines or that

453 the limiting factors for Golden-winged Warbler population growth exist outside the breeding season,

454 or both.

Our study occurred at only a single management and control site in 1 study area, and it is

456 possible that the vegetation management at our study area, or the response of Golden-winged

457 Warblers at our study area, was unique and not representative of the response of Golden-winged

458 Warblers to vegetation management implemented as part of the $\mathrm{ABC}$ initiative as a whole. However, 459 a post-management report from individuals involved with the initiative includes our study site as one 460 of many sites where "shrub management" was used to "create habitat for Golden-winged Warblers"

461 (Larkin et al. 2016, pg. 3,18), and shrub management was the primary method used on public lands

462 during this initiative (Diesser 2017), indicating that those who implemented the management and are

463 conducting post-management surveys identify the management at our study site as standard, and

464 furthermore described it as successful with respect to Golden-winged Warblers (Larkin et al. 2016).

465 It is not clear whether results like ours could have been identified if management had not 466 occurred on a study site where Golden-winged Warblers were already intensively studied, as the 467 ABC initiative protocols in Minnesota did not include pre-management bird surveys. The post468 management surveys being conducted as part of the $\mathrm{ABC}$ initiative are designed only to detect the 
469 presence of Golden-winged Warblers and secondary species purported to benefit from the

470 management (Larkin et al. 2016). Without pre-management data and data from control sites, there is

471 little insight to be gained about the effects of management based solely on post-management surveys

472 for species presence. In this instance, Golden-winged Warblers persisted at our study area following

473 management, and post-management assessment could erroneously conclude that they responded

474 positively to management based solely on presence following management. Although our spatially

475 explicit models of full-season productivity are locally and biologically informed and have been

476 validated in our study region to be predictive of observed productivity (Peterson et al. 2016), direct

477 studies of full-season productivity at a sample of managed sites would be necessary to determine the

478 full effect of ABC initiative management in Minnesota and the broader western Great Lakes region

479 and elsewhere. To our knowledge, there are no current plans to fund or conduct such an assessment.

480 The long-term stability and strong productivity of Minnesota's Golden-winged Warbler population

481 and the results of our monitoring and analysis suggest that the $\mathrm{ABC}$ initiative management in

482 Minnesota is likely not meeting its stated goals and is, at least at one representative site, producing

483 conditions that result in negative impacts on the target species.

\section{Conclusion}

485 We suggest that there are several important implications from our assessment. First, we think this

486 highlights the possible negative consequences of basing management prescriptions on plans

487 developed in ecologically and geographically disparate systems. For example, it is possible that

488 mechanical clearing of shrublands produces the ABC initiative's intended outcome in other regions,

489 but is known not to do so in Minnesota (Hanowski et al. 1999). In addition, not incorporating

490 appropriate assessment efforts may obfuscate the effects of management, and worse, may result in

491 incorrect conclusions about management effects on target populations. For example, the Larkin et al. 
492 (2016) report includes our study site as successful management because they detected $\geq 1$ Golden-

493 winged Warbler during surveys following the management. Furthermore, not incorporating local and

494 regional information about factors that influence succession (e.g., local soil types, vegetation growth

495 rates, etc.) into management plans may increase the period over which management activities affect

496 target populations, and in this case, extend the period of reduced Golden-winged Warbler abundance

497 and productivity. Although attractive to planners and managers, overly precise management

498 prescriptions that fail to incorporate local circumstances and diverse conservation needs can lead to

499 expensive and expansive conservation failures (Hiers et al. 2016) and even extinctions (Woinarski et

500 al. 2017). For Golden-winged Warblers in the western Great Lakes region, we suggest that

501 conservation plans based on information derived from a narrow period of the species' breeding cycle

502 in a distant portion of the breeding distribution be critically reviewed and that local and regional

503 information be incorporated prior to implementation, if management is deemed necessary at all, to

504 avoid applying management prescriptions that may have the opposite of intended effects.

\section{Acknowledgments}

506 We thank the J. Refsnider lab and anonymous reviewers for constructive comments on the

507 manuscript. Our assessment was of the outcomes of Golden-winged Warbler management at Rice

508 Lake NWR where we had data to evaluate a specific management action and neither the authors nor

509 the U.S. Geological Survey, The University of Toledo, The University of Minnesota, The University

510 of California, Berkeley, or any organization supporting our work intend to impugn the motives of

511 organizations sponsoring or conducting the management we assessed. Rather, our intention is to use

512 our opportunity to evaluate effects of a regional management initiative on a species of high

513 conservation concern, in the hopes that management plans and programs can adapt their objectives 
514 and methods to better address high-priority conservation needs. Use of trade names does not imply

515 endorsement by the U.S. Geological Survey or the University of Minnesota.

\section{References}

517 Aldinger KR, Wood PB. 2014. Reproductive success and habitat characteristics of Golden-winged

518 Warblers in high-elevation pasturelands. Wilson Journal of Ornithology 127:279-287.

519 Aldinger KR, Terhune II TM, Wood PB, Buehler DA, Bakermans MH, Confer JL, Flaspohler DJ,

520 Larkin JL, Loegering JP, Percy KL, Roth AM, Smalling CG. 2015. Variables associated with

521 nest survival of Golden-winged Warblers (Vermivora chrysoptera) among vegetation

522 communities commonly used for nesting. Avian Conservation and Ecology 10:art6.

523 Bonnot TW, Thompson III FR, Millspaugh JJ, Jones-Farrand DT. 2013. Landscape-based population

524 viability models demonstrate importance of strategic conservation planning for birds.

$525 \quad$ Biological Conservation 165:104-114.

526 Buehler DA, Roth AM, Vallender R, Will TC, Confer JL, Canterbury RA, Barker-Swarthout S.,

527 Rosenberg KV, Bullock LP. 2007. Status and conservation priorities of Golden-winged

528 Warbler (Verminora chrysoptera). Auk 124:1439-1445.

529 Bulluck LP, Buehler DA. 2008. Factors influencing Golden-winged Warbler (Vermivora

530 chrysoptera) nest-site selection and nest survival in the Cumberland Mountains of Tennessee.

$531 \quad$ Auk 125:551-559.

532 Cohen EB, Lindell CA. 2004. Survival, habitat use, and movements of fledgling White-throated

533 Robins (Turdus assimilis) in a Costa Rican agricultural landscape. Auk 121:404-414.

534 Confer JL, Barnes KW, Alvey EC. 2010. Golden- and Blue-winged Warblers: distribution, nesting

535 success, and genetic differences in two habitats. Wilson Journal of Ornithology 122:273-278. 
536 Confer JL, Hartman P, Roth A. 2011. Golden-winged Warbler (Vermivora chrystoptera). In A.

537 Poole (Ed.), The birds of North America online. Cornell Lab of Ornithology, Ithaca, NY. 538 https://birdsna.org (accessed 1/9/2017).

539 Cornell Lab of Ornithology. 2016. Golden-winged Warbler: conservation strategy. 540 http://www.birds.cornell.edu/page.aspx?pid=2679 (accessed 1/9/2017).

541 Crawford DL, Rohrbaugh RW, Roth AM, Lowe JD, Barker-Swarthout S, Rosenberg KV. 2016. 542 Landscape-scale habitat and climate correlates of breeding Golden-winged and Blue-winged Warblers. Studies in Avian Biology 49:41-66.

544

545

546

547

548

549

550

551

552

553

554

555

556

557 558

Donner DM, Ribic CA, Probst JR. 2010. Patch dynamics and the timing of colonizationabandonment events by male Kirtland's Warblers in an early succession habitat. Biological Conservation 143:1159-1167.

Dieser P. 2017. Restoring habitat for Minnesota's Golden-winged Warblers. News and Perspectives on Bird Conservation. American Bird Conservancy. www.abcbirds.org.

Fearer T. 2016. Appalachian Mountains Joint Venture year in review. http://amjv.org/index.php/Library/712/ (accessed 1/9/2016).

Ficken MS, Ficken RW. 1968. Territorial relationships of Blue-winged Warblers, Golden- winged Warblers, and their hybrids. Wilson Bulletin 80:442-451.

Hanowski JM, Christian DP, Nelson MC. 1999. Response of breeding birds to shearing and burning in wetland brush ecosystems. Wetlands 19: 584-593.

Hiers JK, Jackson ST, Hobbs RJ, Bernhardt ES, Valentine LE. 2016. The precision problem in conservation and restoration. Trends in Ecology and Evolution 31:820-830.

Jackson AK, Froneberger JP, Cristol DA. 2013. Habitat near nest boxes correlated with fate of Eastern Bluebird fledglings in an urban landscape. Urban Ecosystems 16: 367-376. 
559 Johns R, Wieber K, Otto B. 2015. \$10 Mil. forest restoration project will benefit imperiled Golden-

560 winged Warbler. American Bird Conservancy. https://abcbirds.org/article/10-mil-forest-

561 restoration-project-will-benefit-imperiled-golden-winged-warbler/ (accessed 1/9/2016).

562 Johnson DH. 1999. The insignificance of statistical significance testing. Journal of Wildlife

$563 \quad$ Management 63:763-772.

564 Johnson M, Stone B, Brandt W, Fink D, Landwehr T, Lepper C, Schmidt S, Umphress T, Martinson

565 L, Engwall C, Epperly D, Schad D, Vadis M. 2008. Minnesota forests for the future:

566

567 conserving Minnesota's working forest lands to meet the state's future recreation, economic, and ecological needs. Minnesota Department of Natural Resources, Minnesota, USA.

569

Kramer, GR, Streby HM, Peterson SM, Lehman JA, Buehler DA, Wood PB, McNeil DJ, Larkin JL, Andersen DE. 2017. Nonbreeding isolation and population-specific migration patterns among three populations of Golden-winged Warblers. The Condor: Ornithological Applications 119:108-121.

572

Kubel JE, Yahner RH. 2008. Quality of anthropogenic habitats for Golden-winged Warblers in

574

575

576

577

578

579

580

581 central Pennsylvania. Wilson Journal of Ornithology 120:801-812.

Larkin J, McNeil Jr. DJ, Johnson K, Rodewald A, Lott C, Dayer A, Lutter S. 2016. Annual report assessing wildlife response to NRCS conservation programs targeting early successional habitats. A conservation effects assessment project. Indiana University of Pennsylvania, Indiana, PA, USA.

Lyons JK, Runge MC, Lasckowski HP, Kendall WL. 2008. Monitoring in the context of structured decision-making and adaptive management. Journal of Wildlife Management 72:1683-1692. MacSwain J. 2016. More boots on the ground to help declining songbird in Minnesota. USDA Natural Resources Conservation Service. 
582

583

584

585

586

587

588

589

590

591

592

593

594

595

596

597

598

599

600

601

602

https://www.nrcs.usda.gov/wps/portal/nrcs/blogdetail/nrcsblog/home/?cid=NRCSEPRD1182 008 (accessed 1/10/2016).

Miles PD, VanderSchaaf CL. 2012. Minnesota's forest resources, 2011. USDA Forest Service, Northern Research Station Research Note NRS-134. Newtown Square, Pennsylvania, USA.

Niemi GJ, Howe RW, Sturtevant BR, Parker LR Grinde AR, Danz NP, Nelson MD, Zlonis EJ, Walton NG, Gnass Giese EE, Lietz SM. 2016. Analysis of long-term forest bird monitoring data from national forests of the western Great Lakes Region. General Technical Report NRS-159. USDA Forest Service. Newtown Square, PA.

NRCS Soil Survey Staff. 2016. Web Soil Survey. Natural Resources Conservation Service, United States Department of Agriculture. http://websoilsurvey.nrcs.usda.gov/ (accessed 1/9/2016).

Peterson SM. 2014. Landscape productivity and the ecology of brood division in Golden-winged Warblers in the western Great Lakes region. 2014. University of Minnesota, Minneapolis, USA.

Peterson SM, Kramer GR, Streby HM, Lehman JA, Buehler DA, Andersen DE. 2015. Geolocators on Golden-winged Warblers do not affect migratory ecology. Condor: Ornithological Applications 117:256-261.

Peterson SM, Streby HM, Andersen DE. 2016a. Spatially explicit models of full-season productivity and implications for landscape management of Golden-winged Warblers in the western Great Lakes region. Studies in Avian Biology 49:141-161.

Peterson SM, Streby HM, Andersen DE. 2016b. Management implications of brood division in Golden-winged Warblers. Studies in Avian Biology 49:161-171. 
603 Rohrbaugh RW, Buehler DA, Barker Swarthout S, King DI, Larkin JL, Rosenberg KV, Roth AM, 604 Vallender R, Will T. 2016. Conservation perspectives: review of new science and primary 605 threats to Golden-winged Warblers. Studies in Avian Biology 49:207-215.

606 Rosenberg KV, Will T, Buehler DA, Barker Swarthout S, Thogmartin WE, Bennett RE, Chandler 607 RB. 2016. Dynamic distributions and population declines of Golden-winged Warblers. Studies in Avian Biology 49: 3-28.

609

610

611

612

613

614

615

616

617

618

619

620

621

622

623

624
Rossell Jr. CR, Patch SC, Wilds SP. 2003. Attributes of Golden-winged Warbler territories in a mountain wetland. Wildlife Society Bulletin 31:1099-1104.

Roth, A. M., R. W. Rohrbaugh, T. Will, and D. A. Buehler. 2012. Golden-winged Warbler Status Review and Conservation Plan. <www.gwwa.org> (accessed 10 January 2016).

Sauer JR, Hines JE, Fallon JE, Pardieck KL, Ziolkowski Jr. DJ, Link WA. 2014. The North American Breeding Bird Survey, Results and Analysis 1966-2013. Version 01.30.2015. USGS Patuxent Wildlife Research Center, Laurel, Maryland, USA.

Schulte LA, Mladenoff DJ, Crow TR, Merrick LC, Cleland DT. 2007. Homogenization of northern U.S. Great Lakes forests due to land use. Landscape Ecology 22:1089-1103.

Shaffer TL. 2004. A unified approach to analyzing nest success. Auk 121:526-540.

Streby HM, Peterson SM, McAllister TL, Andersen DE. 2011. Use of early-successional managed northern forest by mature-forest species during the post-fledging period. Condor 113:817824.

Streby HM, Refsnider JM, Peterson SM, Andersen DE. 2014. Retirement investment theory explains patterns in songbird nest-site choice. Proceedings of the Royal Society of London B 281: 20131834. 
625 Streby HM, Loegering JP, Andersen DE. 2012. Spot mapping underestimates song-territory size and 626 use of mature forest by breeding Golden-winged Warblers in Minnesota, USA. Wildlife $627 \quad$ Society Bulletin 36: 40-46.

628 Streby HM, Peterson SM, Kramer GR, Andersen DE. 2015. Post-independence fledgling ecology in 629 a migratory songbird: implications for breeding-grounds conservation. Animal Conservation $630 \quad 18: 228-235$.

631 Streby HM, Rohrbaugh RW, Buehler DA, Andersen DE, Vallender R, King DI, Will T. 2016. 632 Research on golden-winged warblers: recent progress and current needs. Studies in Avian 633 Biology 49:217-227.

634 Terhune II TM, Aldinger KR, Buehler DA, Flaspohler, DJ Larkin JL, Loegering JP, Percy KL, Roth 635 AM, Smalling C, Wood PB. 2016. Golden-winged warbler nest-site habitat selection. Studies 636 in Avian Biology 49:109-125.

Van Horne B. 1983. Density as a misleading indicator of habitat quality. Journal of Wildlife Management 47:893-901.

639

640

641

642

643

644 645 646 647

Woinarski JCZ, Garnett ST, Legge SM, Lindenmayer DB. 2017. The contribution of policy, law, management, research, and advocacy failings to the recent extinctions of three Australian vertebrate species. Conservation Biology 31: 13-23.

Zlonis EJ, Grinde A, Bednar J, Niemi GJ. 2013. Summary of breeding bird trends in the Chippewa and Superior National Forests of Minnesota - 1995-2013. NRRI technical report NRRI/TR2013/36, University of Minnesota Duluth, USA.

\section{Figure Legends}

Figure 1. Trends in Golden-winged Warbler counts along routes sampled during the Breeding Bird Survey (Sauer et al. 2014) from 1966 - 2013. Modeled numbers of birds per BBS survey route (open 
648 circles) and 95\% credible intervals are displayed for A) the global population, B) the Appalachian

649 breeding distribution segment, which comprises $<5 \%$ of the global population, and C) the

650 Minnesota breeding population, which comprises $\sim 50 \%$ of the global population. Urgent calls for

651 Golden-winged Warbler conservation action often cite the global trend (A), which has stabilized in

652 recent years because western populations remain stationary or increasing and the influence of the

653 Appalachian population on global trends has decreased as that population asymptotes toward zero.

654

655 Figure 2. Vegetation at Rice Lake National Wildlife Refuge in Minnesota A) before and B) 2 years

656 after management by the ABC Initiative, and C) an area managed with the same management

657 prescription in Bald Eagle State Park in Pennsylvania. Inset in A demonstrates the complexity in pre-

658 management vegetation structure. Image $\mathrm{C}$ demonstrates that management in Minnesota replicated

659 vegetation structure of similarly managed areas in the Appalachian region. Photos by H. Streby (A

660 and inset) and G. Kramer (B and C).

661

662 Figure 3. Core breeding territories of Golden-winged Warbler pairs at our main study site at Rice

663 Lake National Wildlife Refuge A) annually from $2011-2014$ ( $n=62$ pairs) before ABC Initiative

664 management, and B) $2015(n=45$ pairs $)$ and C) $2016(n=45$ pairs $)$, the 2 years following

665 management. These core breeding territories were delineated based on spot-mapping, song- and call-

666 broadcast, mist-netting, and observations of nest building, nestling feeding, and territorial behavior,

667 are intended for census information, and do not represent total area used by birds for their song

668 territories or home ranges (Streby et al. 2012). Base map from ESRI World Imagery (all 3 images

669 are identical for ease of comparison of bird counts, thus the base maps are not intended to display

670 management). 
671

672 Figure 4. Productivity surfaces derived from spatially explicit full-season productivity models for

673 Golden-winged Warblers breeding at our main study site at Rice Lake National Wildlife Refuge,

674 Minnesota, USA A) before and B) after management implemented by the ABC initiative to benefit

675 the species. Non-nesting area (hatched) is comprised of roads, gravel parking areas, and grassland

676 and productivity values from non-nesting areas are not included in total productivity estimates.

677 Management increased the amount of non-nesting area and decreased productivity for the remaining 678 nesting area from 1.45 fledglings raised to independence per breeding pair prior to management to 6791.04 fledglings per pair immediately after management. Base map from ESRI World Imagery (both 680 images are identical for ease of comparison of model outputs, thus the base maps are not intended to 681 display management). 


\section{Figure 1}

Long-term population trends for Golden-winged Warblers by region and globally from the Breeding Bird Survey

Trends in Golden-winged Warbler counts along routes sampled during the Breeding Bird Survey (Sauer et al. 2014) from 1966 - 2013. Modeled numbers of birds per BBS survey route (open circles) and $95 \%$ credible intervals are displayed for $A$ ) the global population, B) the Appalachian breeding distribution segment, which comprises $<5 \%$ of the global population, and C) the Minnesota breeding population, which comprises $\sim 50 \%$ of the global population. Urgent calls for Golden-winged Warbler conservation action often cite the global trend $(A)$, which has stabilized in recent years because western populations remain stationary or increasing and the influence of the Appalachian population on global trends has decreased as that population asymptotes toward zero. 

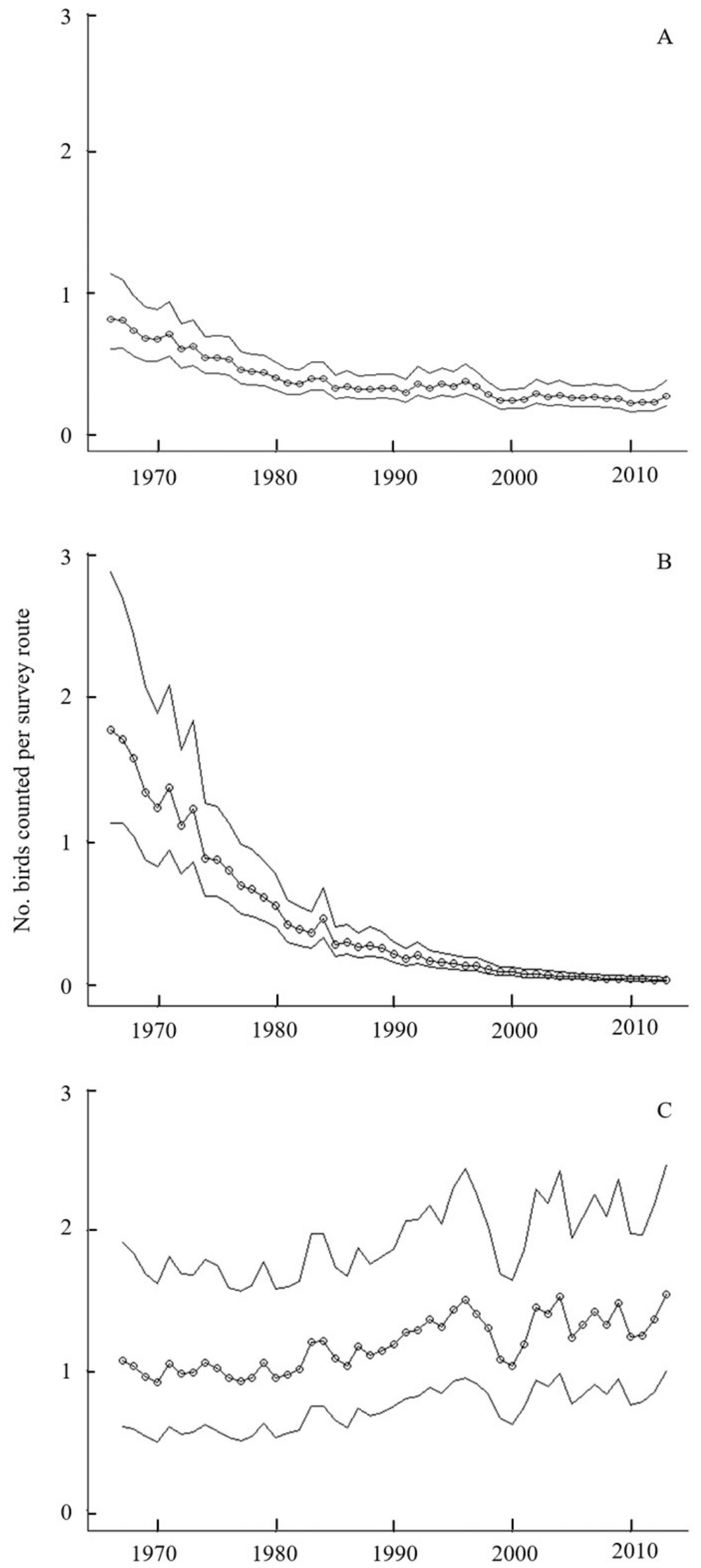

PeerJ reviewing PDF | (2017:11:22 N45:2:0:NEW 6 Jan 2018) 


\section{Figure 2}

The study site before and after management and a comparable area managed under the same prescription with the same result.

Vegetation at Rice Lake National Wildlife Refuge in Minnesota A) before and B) 2 years after management by the $A B C$ Initiative, and $C$ ) an area managed with the same management prescription in Bald Eagle State Park in Pennsylvania. Inset in A demonstrates the complexity in pre-management vegetation structure. Image $\mathrm{C}$ demonstrates that management in Minnesota replicated vegetation structure of similarly managed areas in the Appalachian region. Photos by $H$. Streby ( $A$ and inset) and G. Kramer ( $B$ and $C$ ).

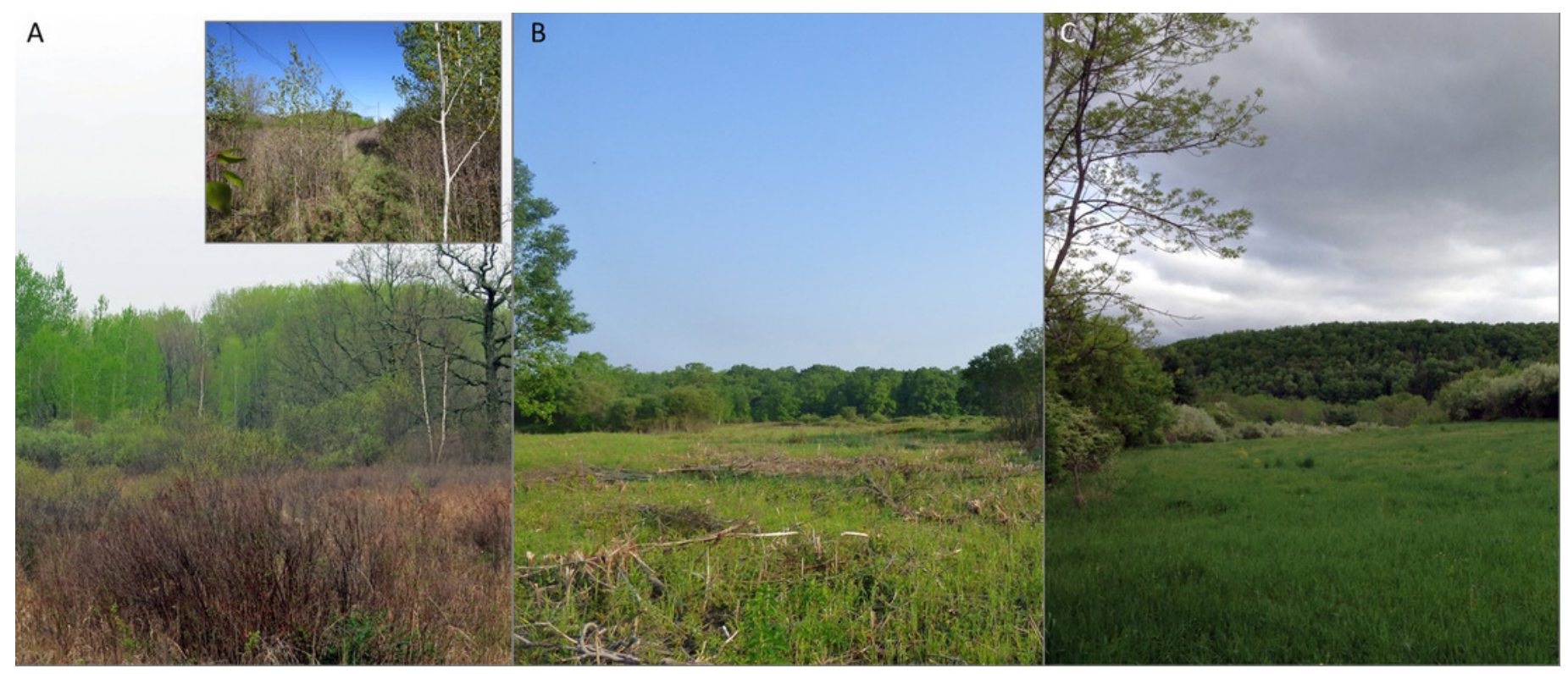




\section{Figure 3}

Core territories of breeding pairs of Golden-winged Warblers before and after management

Core breeding territories of Golden-winged Warbler pairs at our main study site at Rice Lake National Wildlife Refuge A) annually from 2011 - 2014 ( $n=62$ pairs) before ABC Initiative management, and B) 2015 ( $n=45$ pairs) and C) 2016 ( $n=45$ pairs), the 2 years following management. These core breeding territories were delineated based on spot-mapping, songand call-broadcast, mist-netting, and observations of nest building, nestling feeding, and territorial behavior, are intended for census information, and do not represent total area used by birds for their song territories or home ranges (Streby et al. 2012). Base map from ESRI World Imagery (all 3 images are identical for ease of comparison of bird counts, thus the base maps are not intended to display management).

*Note: Auto Gamma Correction was used for the image. This only affects the reviewing manuscript. See original source image if needed for review.

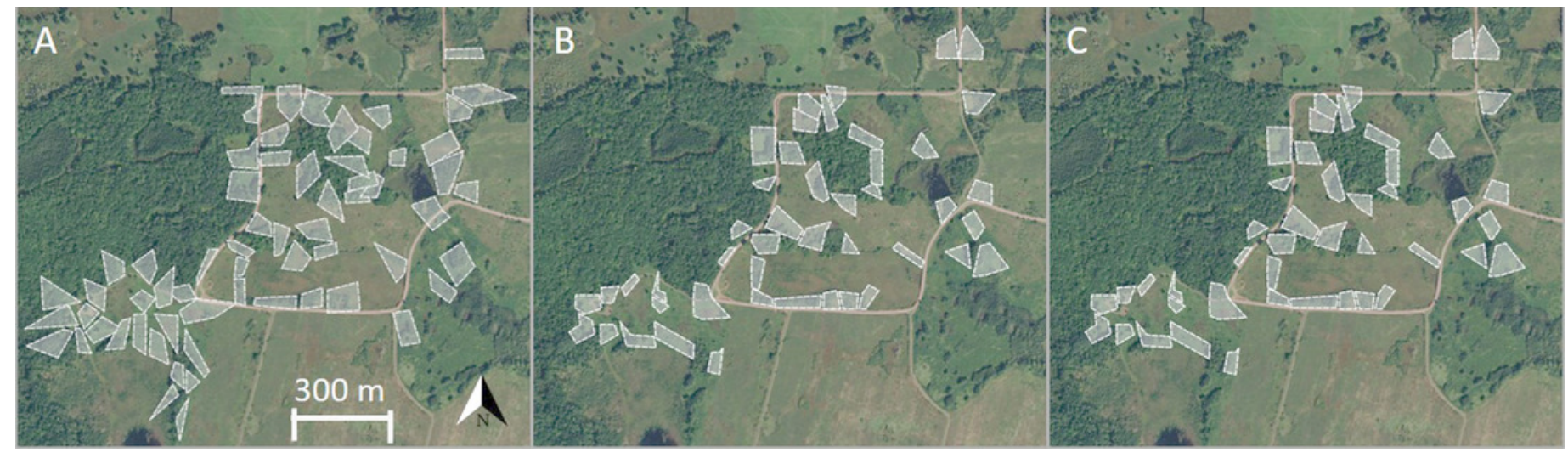




\section{Figure 4}

Spatially explicit model of full-season productivity for Golden-winged Warblers breeding in the study area before and after management.

Productivity surfaces derived from spatially explicit full-season productivity models for Golden-winged Warblers breeding at our main study site at Rice Lake National Wildlife Refuge, Minnesota, USA A) before and B) after management implemented by the $A B C$ initiative to benefit the species. Non-nesting area (hatched) is comprised of roads, gravel parking areas, and grassland and productivity values from non-nesting areas are not included in total productivity estimates. Management increased the amount of non-nesting area and decreased productivity for the remaining nesting area from 1.45 fledglings raised to independence per breeding pair prior to management to 1.04 fledglings per pair immediately after management. Base map from ESRI World Imagery (both images are identical for ease of comparison of model outputs, thus the base maps are not intended to display management). 

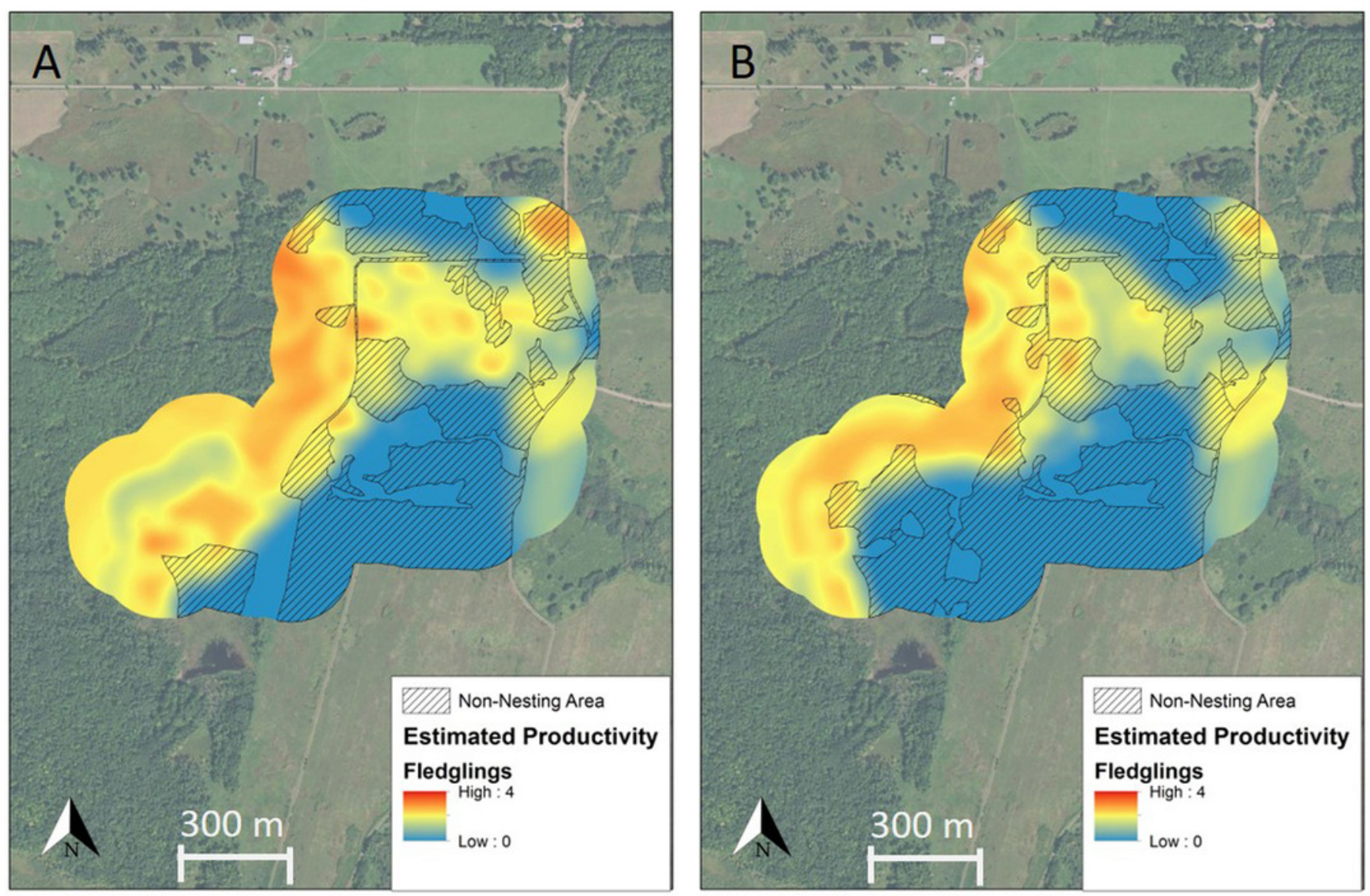